\title{
IDENTIFICATION OF STABLE AND ADAPTABLE HYBRID RICE GENOTYPES
}

\author{
M. J. Hasan, M. U. Kulsum ${ }^{*}$, M. M. Hossain ${ }^{1}$ and Z. Akond ${ }^{2}$, M. M. Rahman ${ }^{3}$ \\ Hybrid Rice, Plant Breeding Division, Bangladesh Rice Research Institute
}

\begin{abstract}
Development of varieties with high yield potential coupled with wide adaptability is an important plant breeding objective. Presence of genotype and environment $(\mathrm{G} \times \mathrm{E})$ interaction plays a crucial role in determining the performance of genetic materials, tested in different locations in different years. This study was under taken to assess yield performance, stability and adaptability of seventeen hybrid rice genotypes evaluated over 12 environments. The analysis of variance for growth duration and grain yield $\left(\mathrm{t} \mathrm{ha}^{-1}\right)$ for genotype, environment year, environment $\times$ genotype, year $\times$ environment, year $\times$ genotype and year $x$ environment $\times$ genotype were highly significant $(p<0.01)$ showing the variable response of the genotype across environments and year. GE interaction patterns revealed by AMMI biplot analysis indicated that the hybrid rice genotypes are broadly adapted. Genotypes BRRI53A/BRRI26R, Jin23A/507R, Jin23A/BR7881-25-2-3-12 and IR79156A/F2277R were best for the environment: Gazipur and Rangpur at second and third year. Genotypes Jin23A/PR344R, BRRI11A/AGR and IR79156A/BRRI20R showing high yield performance and widely adapted to all environments.
\end{abstract}

Key words: Adaptation, Hybrid rice, AMMI analysis, GEI, PCA.

\section{INTRODUCTION}

Development of varieties with high yield potential coupled with wide adaptability is an important plant breeding objective. Genotype by environment $(\mathrm{G} \times \mathrm{E})$ interaction plays a crucial role in determining the performance of genetic materials, tested in different locations and in different years, influencing the selection process (Purchase et al., 2000). Multilocation trials provide useful information on genotypic adaptation and stability. The $\mathrm{G} \times \mathrm{E}$ interaction estimates help breeders to

\footnotetext{
*Corresponding author email: umkh332china@gmail.com

${ }^{1}$ Assistant Information Officer, Agriculture Information Service, Khamarbari, Farmgate, Dhaka-1215

${ }^{2}$ Scientific Officer, ASICT, BARI, Gazipur-1701

${ }^{3}$ Principal Training Officer, BARC, Farmgate, Dhaka- 1215
}

Received: 21.11.2013 
decide the breeding strategy, to breed for specific or general adaptation, which depends on stability in yield performance under a limited or wide range of environmental conditions.

The AMMI model is a hybrid analysis that incorporates both additive and multiplicative components of the two way data structure. AMMI is the only model that distinguishes clearly between the main and interaction effects and this is usually desirable in order to make reliable yield estimations (Gauch, 1992). AMMI biplot analysis is considered to be an effective tool to diagnose GE interaction pattern graphically. The AMMI model describes the GE interaction in more than one dimension and it offers better opportunities for studying and interpreting GE interaction than analysis of variance (ANOVA) and regression of the mean. In AMMI additive portion is separated from interaction by ANOVA. Then the Interaction Principle Components Analysis (IPCA), which provides a multiplicative model, is applied to analyze the interaction effect from the additive ANOVA model. The biplot display of IPCA scores plotted against each other provides visual inspection and interpretation of the GE interactions. Integrating biplot display and genotypic stability statistics enables genotypes to be grouped based on similarity of performance across diverse environments.

Concerning the use of AMMI in METs (multi-environmental trials) data analysis, which partitions the GE interaction matrix into individual genotypic and environmental scores, an example was provided by Zobel et al. (1988), who studied the GE interaction of a soybean MET. Among multivariate methods, AMMI analysis is widely used for GE interaction investigation. The biplot shows both the genotypes and the environments value and relationship using singulars vectors technique (Tarakanovas and Ruzgas, 2006).

This study was undertaken to interpret GE interaction obtained by AMMI analysis of yield performance of 17 hybrid rice genotypes over 12 environments, visually assess how to vary yield performances across environments based on the biplot and group the genotypes having similar response pattern across environments.

\section{MATERIALS AND METHOD}

The experiments were conducted under breeding division of Bangladesh Rice Research Institute (BRRI) at four different agro-ecological zones in the country for three years (2008-09, 2009-10, 2010-11: table1). Seventeen commercial rice varieties including two inbred BRRI dhan28 and BRRI dhan29 as checks and 15 hybrid varieties were evaluated. The experiments were carried out in a randomized complete block design, with three replications. Each experimental plot was comprised of $5 \times 6$ $\mathrm{m}$. Standard agronomic practices were followed and plant protection measures were taken as and when required. Two border rows were used to minimize the border effects. Ten randomly selected plants were used for recording observations on plant 
height $(\mathrm{cm})$. The grain yield $\left(\mathrm{t} \mathrm{ha} \mathrm{h}^{-1}\right)$ data was estimated and corrected at $14 \%$ moisture.

Table 1: Code, name of each genotype, environment and growing years

\begin{tabular}{|c|c|c|c|c|c|c|}
\hline Env & $\begin{array}{c}\text { Cropping } \\
\text { season }\end{array}$ & Location & $\begin{array}{c}\text { Code of } \\
\text { Env }\end{array}$ & $\begin{array}{c}\text { Genotype } \\
\text { no. }\end{array}$ & Genotype & $\begin{array}{c}\text { Code of } \\
\text { genotype }\end{array}$ \\
\hline 1 & 2008-09 & Gazipur & A & 1 & BRRI7A/BR1543-1-1-1-1 & G1 \\
\hline 2 & 2009-10 & Gazipur & B & 2 & BRRI11A/F2277R & G2 \\
\hline 3 & $2010-11$ & Gazipur & $\mathrm{C}$ & 3 & BRRI11A/BR1543-1-1-1-1 & G3 \\
\hline 4 & 2008-09 & Rangpur & $\mathrm{D}$ & 4 & BRRI13A/PR828R & G4 \\
\hline 5 & $2009-10$ & Rangpur & $\mathrm{E}$ & 5 & BRRI28A/BRRI26R & G5 \\
\hline 6 & 2010-11 & Rangpur & $\mathrm{F}$ & 6 & BRRI48A/3028R & G6 \\
\hline 7 & 2008-09 & Comilla & G & 7 & BRRI48A/BRRI26R & G7 \\
\hline 8 & $2009-10$ & Comilla & $\mathrm{H}$ & 8 & BRRI33A/BRRI31R & G8 \\
\hline 9 & 2010-11 & Comilla & I & 9 & Jin23A/PR344R & G9 \\
\hline 10 & 2008-09 & Satkhira & $\mathrm{J}$ & 10 & BRRI11A/AGR & G10 \\
\hline 11 & $2009-10$ & Satkhira & K & 11 & IR79156A/BRRI20R & G11 \\
\hline \multirow[t]{6}{*}{12} & $2010-11$ & Satkhira & $\mathrm{L}$ & 12 & BRRI53A/BRRI26R & G12 \\
\hline & & & & 13 & Jin23A/BR7881-25-2-3-12 & G13 \\
\hline & & & & 14 & $\operatorname{Jin} 23 \mathrm{~A} / 507 \mathrm{R}$ & G14 \\
\hline & & & & 15 & IR79156A/F2277R & G15 \\
\hline & & & & 16 & BRRI dhan28 & G16 \\
\hline & & & & 17 & BRRI dhan29 & G17 \\
\hline
\end{tabular}

AMMI model was used to quantify the effect of different factors (genotype, location and year) of the experiment. It uses to make standard ANOVA for separating the additive variance from multiplicative variance (genotype and environment interaction). Thereafter, it uses a multiplicative procedure- PCA- to extract the pattern from the $\mathrm{G} \times \mathrm{E}$ portion of the ANOVA (Zobel et al., 1988). The AMMI model is:

$$
Y_{g e}=\mu+\alpha_{g}+\beta_{e}+\sum_{n=1}^{N} \lambda n \gamma_{g n} \delta_{e n}+\rho_{g e}
$$


M. J. Hasan et al.

Where:

$Y_{g e}=$ yield of the genotype $(\mathrm{g})$ in the environment (e)

$\mu=$ grand mean

$\alpha_{g}=$ genotype mean deviation

$\beta_{e}=$ environment mean deviation

N= No. of IPCAs (Interaction Principal Component Axis) retained in he model.

$\lambda n=$ singular value for IPCA axis $\mathbf{n}$

$\gamma_{g n}=$ genotype eigenvector values for IPCA axis $\mathbf{n}$

$\delta_{e n}=$ environment eigenvector values for IPCA axis $\mathbf{n}$

$\rho_{g e}=$ the residuals

The model further provides graphical representation of the numerical results (Biplot analysis) with a straight-forward interpretation of the underlying causes of $\mathrm{G}$ x E (Gauch, 1998).

\section{RESULTS}

Analysis of variance was done to determine the effects of year, location, genotypes and interaction among these factors on growth duration and grain yield of promising hybrid rice genotypes. There were genotype $\times$ location, year $\times$ location, year $\times$ genotype and three way interaction, genotype $\times$ location $\times$ year significant for growth duration and grain yield $(\mathrm{p}<0.01$; Table 2$)$. However, genotypic main effect averages are presented in table and even in the presence of cross-over interactions in a data set, when it comes to select widely adapted genotypes, breeders are interested in selecting lines with high genotypic effect (average over location and years) and with low fluctuation in yield or other traits of interest (stable).

The effects of genotype $\times$ environment interaction could be divided into four components, ie. IPCA1, IPCA2, IPCA3 and IPCA4 where first three components were significantly different for yield but last component were not significant (Table 3 ). In case of growth duration IPCA1 is significant but IPCA2, IPCA3 and IPCA4 were not significant. The variation in soil structure and moisture across the different environments were considered as a major under lying causal factors for the $\mathrm{G} \times \mathrm{E}$ interaction.

Among the genotypes BRRI7A/BR1543-1-1-1-1,BRRI11A/F2277R, BRRI11A/BR1543-1-1-1-1 and BRRI dhan28 showed negative phenotypic index $(\mathrm{Pi})$, insignificant regression coefficient (bi) and deviation from regression $\left(\mathrm{S}^{2} \mathrm{di}\right)$ indicating the stability of genotypes over all environments with short growth duration 
(Table 4). Shorter growth duration is favorable for hybrid rice. On the other hand, BRRI13A/PR828R and BRRI48A/3028R showed the negative phenotypic index (Pi), significant regression coefficient (bi) and insignificant deviation from regression ( $\mathrm{S}^{2} \mathrm{di}$ ) indicating shorter growth duration and highly adapted to the environments of Gazipur $3^{\text {rd }}$ year, Rangpur $1^{\text {st }}$ year, Comilla $1^{\text {st }}$ and $3^{\text {rd }}$ year, Satkhira $1^{\text {st }}, 2^{\text {nd }}$ and $3^{\text {rd }}$ year. Variation in grain yield was recorded among genotypes BRRI28A/BRRI26R, Jin23A/PR344R, BRRI11A/AGR, IR79156A/BRRI20R, BRRI53A/BRRI26R and Jin23A/507R showed higher yield as well as stable over environment (Table 5). Genotypes BRRI48A/BRRI26R, Jin23A/BR7881-25-2-3-12, IR79156A/F2277R and BRRI dhan29 were higher yielding but had significant regression coefficient (bi) and non significant deviation from regression $\left(\mathrm{S}^{2} \mathrm{di}\right)$ indicating they are highly responsive to the favorable environments Gazipur $1^{\text {st }}$ year, Comilla $1^{\text {st }}$ year, Satkhira $1^{\text {st }}$ and $3^{\text {rd }}$ year.

As shown table 6, based on IPCA score, a genotype in the AMMI analysis are an indication of the adaptability over environments and association between genotypes and environments can be clearly observed (Albert, 2004). Regardless of positive or negative signs, genotypes with large scores have high interaction and unstable where as genotypes with small scores close to zero have low interaction and stable (Zobel et al., 1988). Thus genotypes BRRI48A/BRRI26R, Jin23A/BR7881-252-3-12 and IR79156A/F2277R have large IPCA scores and are unstable genotypes, whereas the genotypes Jin23A/PR344R, BRRI11A/AGR and IR79156A/BRRI20R have small IPCA1 scores close to zero and are stable. Of the three stable genotypes in IPCA1 scores have a grain yield greater than grand mean. Among the environment Comilla $2^{\text {nd }}$ and $3^{\text {rd }}$ year, Satkhira $1^{\text {st }}, 2^{\text {nd }}$ and $3^{\text {rd }}$ year have small IPCA scores close to zero and are stable. Remaining seven environments have large IPCA1 scores and are unstable environments.

In the AMMI model biplot, the IPCA scores of genotypes and environments are plotted against their respective means, the plot is helpful to visualize the average productivity of the genotypes, environments and their interaction for all possible genotype-environment combinations. The magnitude of interaction can be visualized for each genotype and each environment using IPCA1 vs. IPCA2 biplot model (Yan and Hunt, 1998; Fentie et al., 2013). The AMMI 1 biplot for grain yield of seventeen genotypes at twelve environmental conditions is presented in Fig. 1. AMMI biplot gave a best model for fit of $84.75 \%$. This result is in agreement with the findings of Misra et al., 2009; Chrispus, 2008; Yan and Hunt, 1998; Naveed and Islam, 2007.

According to AMMI biplot environment showed high variation in both main effect and interactions (IPCA1). Environments Gazipur $2^{\text {nd }}$ and $3^{\text {rd }}$ year, Rangpur $1^{\text {st }}$, $2^{\text {nd }}$ and $3^{\text {rd }}$ year have large positive IPCA1 scores, which interact positively with genotypes that had positive IPCA1 scores and negatively those genotypes with negative IPCA1 scores. Environment Gazipur and Comilla $1^{\text {st }}$ year had large negative IPCA1 score which interact positively with genotypes had negative IPCA1 scores 
and negatively with genotypes that had positive IPCA scores. Environment Comilla $2^{\text {nd }}$ and $3^{\text {rd }}$ year, Satkhira $1^{\text {st }}, 2^{\text {nd }}$ and $3^{\text {rd }}$ year have relatively small IPCA1 scores, suggesting that it had little interaction with genotypes indicating stable environment.

The genotypes BRRI28A/BRRI26R, BRRI48A/BRRI26R, BRRI53A/ BRRI26R, Jin23A/BR7881-25-2-3-12, Jin23A/507R and IR79156A/F2277R had higher average yields and these genotypes adapted to favorable environments. Genotypes Jin23A/PR344R, BRRI11A/AGR and IR79156A/BRRI20R placed closer to the biplot origin and were, therefore the most stable, but had average main effects close to the grand mean. Genotypes BRRI48A/3028R, BRRI33A/BRRI31R and BRRI dhan29 had relatively higher average mean grain yield but had large IPCA1 scores, which made them unstable genotypes. Genotypes BRRI7A/BR1543-1-1-1-1, BRRI11A/F2277R, BRRI11A/ BR1543-1-1-1-1, BRRI13A/PR828R and BRRI dhan 28 had low yield and large IPCA1 scores, which are unstable. The result is an agreement with the findings by Alberts, 2004; Misra et al., 2009; Yan and Hunt, 1998; Naveed and Islam, 2007; Anandan et al., 2009.

On the basis of AMMI2 the environment felt into four section with respect to the environments Gazipur $2^{\text {nd }}$ and $3^{\text {rd }}$ year for the genotypes BRRI53A/BRRI26R and Jin23A/507R were the best respectively. For the environments of Rangpur $2^{\text {nd }}$ and $3^{\text {rd }}$ year the genotypes of Jin23A/BR7881-25-2-3-12 and IR79156A/F2277R were the best (Figure2). For the environment Rangpur $1^{\text {st }}$ year the genotype BRRI28A/ BRRI26R and BRRI48A/BRRI26R were the best. The specific responsive environments might have been due to evenly distribution of rainfall, temperature, soil and other abiotic stresses. Genotypes located near the plot origin were less responsive than the vertex genotypes. Genotypes Jin23A/PR344R, BRRI11A/AGR and IR79156A/BRRI20R gave the highest average yield (largest IPCA1 scores) but was relatively stable in across environments.

In contrast the non adapted genotypes of BRRI11A/F2277R, BRRI11A/ BR1543-1-1-1-1, BRRI13A/PR828R and BRRI dhan28 low yielded and small IPCA2 score as indicated they are relatively stable. In this fact relative large IPCA2 score and BRRI48A/3028R and BRRI48A/BRRI26R genotypes have unstable. The biplot shows not only the average yield of a genotype but also how it is achieved stability. That is the biplot also shows the yield of a genotype at individual environments.

\section{DISCUSSION}

There are two major strategies for developing genotypes with low $\mathrm{G} \times \mathrm{E}$ interactions. The first in sub-division or stratification of a heterogeneous area into smaller more homogeneous sub-regions, with breeding programs aimed at developing genotypes for specific sub-regions. However, even with this refinement, the level of interaction can remain high, because breeding area does not reduce the interaction of genotypes with locations and years. The second strategy for reducing $G$ 
$\times$ E interaction involved selecting genotypes with better stability across a wide range of environments in order to better predict behaviour (Eberhart and Russell, 1966). Various methods use $\mathrm{G} \times \mathrm{E}$ interaction to facilitate genotype characterization and as a selection index together with the mean yield of the genotypes.

Numerous methods have been used for an understanding of the causes of $\mathrm{G} \times \mathrm{E}$ interaction (van Eeuwijk et al., 1996). Among the multivariate approaches AMMI model is widely used (Mahalingam et al., 2006; Das et al., 2008). The AMMI model describes the GE interaction in more than one dimension and it offers better opportunities for studying and interpreting GE interaction than analysis of variance (ANOVA) and regression of the mean. In AMMI, the additive, portion is separated from interaction by ANOVA. Then the Interaction Principle Components Analysis (IPCA), which provides a multiplicative model, is applied to analyze the interaction effect from the additive ANOVA model. The biplot display of IPCA scores plotted against each other provides visual inspection and interpretation of the GE interactions. Integrating biplot display and genotypic stability statistics enables genotypes to the grouped based on similarity of performance across diverse environments.

In this study the result of AMMI analysis indicated that the AMMI model fits the data well and justifies the use of AMMI2. This made it possible to construct the biplot and calculate genotypes and environments effects (Kaya et al., 2002). The Interaction Principle Component Axes (IPCA) scores of a genotype in the AMMI analysis indicate the stability of a genotype across environments. The closer the IPCA scores to zero, the more stable the genotypes are across their testing environments (Carbonell et al., 2004). In this study, Jin23A/PR344R, BRRI11A/ AGR and IR79156A/BRRI20R gave the higher average yield and small IPCA scores that was relatively stable over the environments. This result is in agreement with the findings of Muthuramu et al., 2011. In contrast the non adapted genotypes of BRRI11A/F2277R, BRRI11A/BR1543-1-1-1-1, BRRI13A/PR828R and BRRI dhan 28 low yielded and small IPCA2 scores as indicated they are relatively stable. In this fact relative large IPCA2 score and BRRI48A/3028R and BRRI dhan29 genotypes have unstable.

The most accurate model for AMMI can be predicted by using the first two IPCAs (Kaya et al., 2002). Conversely, Sivapalan et al. (2000) recommended a predictive AMMI model with the first four IPCAs. These results indicate that the number of the terms to include in an AMMI model cannot specify a prior without first trying AMMI predictive assessment. In general, factors like type of crop, diversity of the germplasm and range of environmental conditions will affect the degree of complexity of the best predictive model (Crossa et al., 1990).

However, the prediction assessment indicated that AMMI with only two interaction principal component axes was the best predictive model (Zobel et al., 1988). Further interaction principal component axes captured mostly noise and 
therefore did not help to predict validation observations. In this study, the interaction of the 17 genotypes with 12 environments was best predicted by the first two principal components of genotypes and environments.

AMMI Stability Value (ASV) is in effect the distance from the coordinate point to the origin in a two dimensional scattergram of IPCA1 scores against IPCA2 scores (Purchase et al., 2000). Stability in itself should however not be the only parameter for selection, as the most stable genotype wouldn't necessarily gives the best yield performance. As example, consider G8 which was the highest yield performance but large IPCA1 value is not stable.

Genotypes evaluation must be conducted in multiple locations for multiple years to fully sample the target environment (Cooper et al., 1997). Genotype in the presence of unpredictable $\mathrm{G} \times \mathrm{E}$ interaction is a perennial problem in plant breeding (Bramel-Cox, 1996). To select for superior genotypes, it seems that there is no easier way other than to test widely (Troyer, 1996) and select for both average yield and stability (Kang, 1997).

\section{CONCLUSION}

In conclusion, the multivariate approaches have shown that the largest proportion of the total variation in grain yield was attributed to environments in this study. Genotypes Jin23A/PR344R, BRRI11A/AGR and IR79156A/BRRI20R had the highest yield and were hardly affected by the GEI effects as a result of which they will perform well across a wide range of environments. Environments Comilla at second and third year and Satkhira at first, second and third year were stable for all the genotypes. Genotypes BRRI53A/BRRI26R, Jin23A/507R, Jin23A/BR7881-25-23-12 and IR79156A/F2277R were specifically adapted to the environment Gazipur second and third year, Rangpur second and third year respectively. Genotypes BRRI7A/BR1543-1-1-1-1, BRRI11A/F2277R, BRRI11A/BR1543-1-1-1-1 and BRRI13A/PR828R were low yielded and unstable these genotypes needed further improvement.

\section{REFERENCES}

Albert, M.J.A. 2004. A Comparison of statistical methods to describe genotype $\times$ environment interaction and yield stability in multi location maize trials. Ph.D. Diss., Department of Plant Sciences (Plant Breeding), Faculty of Natural and Agricultural Sciences of the University of the Free State. Bloemfontein, South Africa, pp: 7-35.

Anandan, A., Eswaran, R., Sabesan, T. and Prakash, M. 2009. Additive main effects and multiplicative interaction analysis of yield performances in rice genotype under coastal saline environments. Advance in Biological Research, 3: 43-47

Bramel-Cox, P.J. 1996. Breeding for reliability of performance across unpredictable environments. In Genotype-by environment Interaction. Kang, M.S. and Gauch, H.G. (Eds). CRC press, Boca Raton, FL, pp. 309-339 
Carbonell, S.A., Filho, J.A., Dias, A.A., Garcia and Morais, L.K. 2004. Common bean genotypes and lines interactions with environments. Science Agriculture. (Piracicaba braz), 61: 169-177

Chrispus, O.A. 2008. Breeding Investigation of Finger millet characteristics including blast disease and striga resistance in Western Kenya, A thesis submitted in partial fulfillment of the requirements for the degree of Doctor of Philosophy (PhD) in Plant Breeding, University of KwaZu; u- Natal Republic of South Africa

Cooper, M., Stucker, R.E., Delacy, I.H. and Harch, B.D. 1997. Wheat breeding nurseries, target environments and indirect selection for grain yield. Crop Science, 37: 1168-1176

Crossa, J., Gauch H.G.and Zobel R.W. 1990. Additive main effects and multiplicative interaction analysis of two international maize genotype trials. Crop Science, 30: 493500

Das, S., Mishra, R.C. and Sinha, S.K. 2008. Variation in seedling growth inhibition due to maleic hydrazide treatment of rice (O. sativa) and ragi (E coracana) genotypes and its relationship with yield and adaptability. Journal of Crop Science Biotechnology, 11(3): 215-222

Eberhart, S. A. and Russel W. A. 1966. Stability parameters for comparing varieties. Crop Science, 6: 36-40

Fentie, M., Assefa, A. and Belete, K. 2013. AMMI analysis of yield performance and stability of finger millet genotypes across different environments. World Journal of Agricultural Science, 9: 231-237

Gauch, H. G. 1998. Model selection and validation for yield trials with interaction. Biometrics, 44: 705-705

Gauch, H.G. 1992. Statistical analysis of regional yield data: AMMI analysis of factorial designs. Elsevier, New York, New York. 278 pages. Chinese edition 2001, China National Rice Research Institute, Hangzhou, China; also includes a Chinese translation of Gauch and Zobel 1997 article on mega-environments in Crop Science, 37: 311-326

Kang, M.S. 1997. Using genotype-by environment interaction for crop genotype development. Advance Agronomy, 62: 199-252

Kaya, Y., Palta, C. and Taner, S. 2002. Additive main effects and multiplicative interaction analysis of yield performance in breed wheat genotypes across environments. Turk Journal of Agriculture, 26: 275-270

Mahalingam, L., Mahendran, S., Chandra, R. and Atlin, G. 2006. AMMI analysis for stability of grain yield in rice (O. sativa L.). International Journal of Botany, 2: 104-106

Misra, R.C., Das, S. and Patnaik, M.C. 2009. AMMI model Analysis of Stability and Adaptability of Late Duration Finger Millet (Eleusine coracana) genotypes. World Applied Science Journal, 6: 1650-1654

Muthuramu, S., Jebaraj, S. and Gnanasekaran, M. 2011. AMMI biplot analysis for drought tolerance in rice (Oryza sativa L.). Research Journal of Agricultural Science, 2: 98-100

Naveed M. Nadeem and Islam, N. 2007. AMMI analysis of some upland cotton genotypes for yield stability in different milieus. World Journal Agricultural Science, 3: 39-44 
Purchase, J.L. Hatting, H. and Van Devanter C.S. 2000. Genotype environment interaction of winter wheat in south Africa: II. Stability analysis of yield performance. South African Journal of Plant Soil, 17: 101-107

Sivapalan, S., Brien L.O., Ferrara G.O., Hollamby G.L., Barclay I. and Martin P.J. 2000. An adaptation analysis of Australian and CIMMYT/ICARDA wheat germplasm in Australian production environments. Australian Journal Agricultural Research, 51: 903-915

Tarakanovas, P. and Ruzgas, V.2006. Additive main effects and multiplicative interaction analysis of grain yield of wheat varieties in Lithuana. Agronomy Research, 4: 91-98

Troyer, A.F. 1996. Breeding for widely adapted popular maize hybrids. Euphytica, 92: 163 174

van Eeuwijk, F.A., Denis, J.B. and Kang, M.S. 1996. Incorporate additional information on genotypes and environments in models for two-way genotype- by environment tables. In: genotype-by Environment Interaction. Kang, M.S. and Gauch, H.G. (Eds.). CRC press, Boca Raton, FL, p. 15-49

Yan, W. and Hunt, L.A. 1998. Genotype by environment interaction and crop yield. Plant Breeding Review, 16: 35-178

Zobel, R.W., Wright M.J. and Gauch H.G. 1988. Statistical analysis of a yield trial. Agronomy Journal, 80: 388-393 
HYBRID RICE GENOTYPES

Table 2: Mean square values of combined analysis of variance (ANOVA) for hybrid rice and their components analyzed over 4 locations in 3 years

\begin{tabular}{l|l|l|l}
\hline \multicolumn{1}{c}{ Source of variation } & \multirow{2}{*}{$\mathbf{d f}$} & \multicolumn{2}{c}{ Mean sum of squares } \\
\cline { 3 - 4 } & & Days to maturity & \multicolumn{1}{c}{ Yield $\left(\mathbf{t ~ h a}^{-\mathbf{1}}\right)$} \\
\hline Year & 2 & $421.36^{* *}$ & $3.29^{* *}$ \\
Location & 3 & $196.61^{* *}$ & $9.93^{* *}$ \\
Replication & 2 & $153.77^{* *}$ & $0.54^{\mathrm{ns}}$ \\
Genotype & 16 & $270.62^{* *}$ & $38.15^{* *}$ \\
Location x Genotype & 48 & $10.78^{* *}$ & $1.14^{* *}$ \\
Year x Location & 6 & $85.52^{* *}$ & $20.32^{* *}$ \\
Year x Genotype & 32 & $17.36^{* *}$ & $0.88^{* *}$ \\
Year x Location x Genotype & 96 & $6.51^{* *}$ & $1.81^{* *}$ \\
Error & 406 & 1.65 & 0.17 \\
\hline
\end{tabular}

** Significant level at $\mathrm{p}<0.01, *$ Significant level at $\mathrm{p}<0.05$

Table 3: Full joint analysis of variance including the partitioning of the $G \times E$ interaction of commercial rice hybrids

\begin{tabular}{|c|c|c|c|}
\hline \multirow[t]{2}{*}{ Source of variation } & \multirow[t]{2}{*}{ df } & \multicolumn{2}{|c|}{ Mean sum of squares } \\
\hline & & Days to maturity & Yield $\left(\mathrm{t} \mathrm{ha}{ }^{-1}\right)$ \\
\hline Genotype (G) & 16 & $90.21 * *$ & $12.72 * *$ \\
\hline Environment (E) & 11 & $58.96^{* *}$ & $4.80^{* *}$ \\
\hline Interaction (GEI) & 176 & $3.22 * *$ & $0.49 * *$ \\
\hline AMMI Component 1 & 26 & $11.25^{* *}$ & $1.87 * *$ \\
\hline AMMI Component 2 & 24 & $3.00 \mathrm{~ns}$ & $0.56^{* *}$ \\
\hline AMMI Component 3 & 22 & $2.56 \mathrm{~ns}$ & $0.37 *$ \\
\hline AMMI Component 4 & 20 & $1.80 \mathrm{~ns}$ & $0.23 \mathrm{~ns}$ \\
\hline G x E (Linear) & 16 & $14.99 * *$ & $2.81 * *$ \\
\hline Pool deviation & 84 & 1.30 & 0.128 \\
\hline Pooled error & 160 & 2.04 & 0.25 \\
\hline
\end{tabular}

** Significant level at $\mathrm{p}<0.01, \mathrm{~ns}=$ Not significant, * Significant level at $\mathrm{p}<0.05$ 
Table 4: Stability analysis for growth duration of 17 commercial rice hybrids over 12 environments.

\begin{tabular}{|c|c|c|c|c|c|c|c|c|c|c|c|c|c|c|c|c|}
\hline \multirow[t]{2}{*}{ Gn } & \multicolumn{12}{|c|}{ Environments } & \multirow{2}{*}{$\begin{array}{c}\text { Over } \\
\text { all } \\
\text { mean }\end{array}$} & \multirow[t]{2}{*}{$\mathbf{P i}$} & \multirow[t]{2}{*}{ bi } & \multirow[t]{2}{*}{$S^{2} d i$} \\
\hline & $\mathbf{A}$ & B & C & D & $\mathbf{E}$ & $\mathbf{F}$ & $\mathbf{G}$ & $\mathbf{H}$ & I & $\mathbf{J}$ & $\mathbf{K}$ & $\mathbf{L}$ & & & & \\
\hline G1 & 149.7 & 150.0 & 147.7 & 148.7 & 150.7 & 152.0 & 148.7 & 151.7 & 147.7 & 149.0 & 151.0 & 151.7 & 149.9 & -0.6 & 0.604 & 1.25 \\
\hline G2 & 151.0 & 150.0 & 146.7 & 147.0 & 150.3 & 152.0 & 148.3 & 152.3 & 146.3 & 150.0 & 152.0 & 151.0 & 149.8 & -0.7 & 0.833 & 2.47 \\
\hline G3 & 149.0 & 149.7 & 146.7 & 148.7 & 150.7 & 150.7 & 151.7 & 153.0 & 149.0 & 149.7 & 149.3 & 149.3 & 149.8 & -0.7 & 0.565 & 1.59 \\
\hline G4 & 150.0 & 150.0 & 147.3 & 148.7 & 150.3 & 152.7 & 148.0 & 151.0 & 149.7 & 151.0 & 151.0 & 148.3 & 149.8 & -0.7 & $0.613^{*}$ & 1.13 \\
\hline G5 & 150.3 & 150.7 & 144.0 & 148.3 & 154.3 & 155.7 & 149.0 & 151.0 & 150.0 & 151.7 & 149.3 & 153.3 & 150.6 & 0.1 & $1.487^{*}$ & 1.73 \\
\hline G6 & 150.0 & 149.3 & 148.3 & 147.7 & 149.3 & 150.7 & 148.0 & 149.7 & 150.0 & 150.0 & 148.7 & 151.0 & 149.4 & -1.1 & $0.306^{*}$ & 0.84 \\
\hline G7 & 148.3 & 152.0 & 147.7 & 149.3 & 155.0 & 155.3 & 147.0 & 151.0 & 151.7 & 151.7 & 152.3 & 148.3 & 150.8 & 0.3 & 0.973 & 4.60 \\
\hline G8 & 152.0 & 151.0 & 150.7 & 151.7 & 151.0 & 151.3 & 152.0 & 151.3 & 151.0 & 151.0 & 151.3 & 152.0 & 151.4 & 0.9 & $0.056^{*}$ & 0.22 \\
\hline G9 & 151.7 & 152.3 & 151.7 & 151.3 & 152.7 & 152.7 & 153.0 & 152.7 & 152.3 & 150.7 & 152.3 & 152.3 & 152.1 & 1.6 & $0.166^{*}$ & 0.40 \\
\hline G10 & 156.3 & 154.0 & 148.0 & 152.7 & 157.0 & 161.7 & 153.3 & 153.0 & 152.7 & 149.7 & 151.3 & 151.7 & 153.4 & 2.9 & 1.664 & 3.63 \\
\hline G11 & 153.0 & 149.0 & 147.7 & 149.0 & 154.7 & 155.0 & 152.0 & 151.3 & 148.0 & 149.7 & 150.0 & 149.7 & 150.8 & 0.3 & 1.166 & 1.46 \\
\hline G12 & 155.7 & 153.0 & 146.7 & 152.0 & 159.7 & 158.7 & 153.0 & 152.7 & 150.0 & 152.0 & 151.7 & 150.0 & 152.9 & 2.4 & $1.769^{*}$ & 2.62 \\
\hline G13 & 153.3 & 150.3 & 144.7 & 147.3 & 153.0 & 154.3 & 152.0 & 150.7 & 152.0 & 151.3 & 150.7 & 151.0 & 150.9 & 0.4 & 1.268 & 1.54 \\
\hline G14 & 153.3 & 151.3 & 144.3 & 147.3 & 158.7 & 157.7 & 153.0 & 152.0 & 149.0 & 149.0 & 149.3 & 150.7 & 151.3 & 0.8 & $2.075^{*}$ & 1.73 \\
\hline G15 & 153.0 & 153.0 & 145.7 & 147.3 & 155.3 & 160.3 & 152.0 & 152.3 & 148.7 & 153.0 & 147.7 & 150.3 & 151.6 & 1.1 & $1.968^{*}$ & 2.81 \\
\hline G16 & 141.7 & 139.3 & 135.3 & 139.7 & 142.7 & 143.3 & 142.0 & 140.0 & 140.0 & 141.3 & 141.3 & 143.3 & 140.8 & -9.7 & 0.973 & 1.76 \\
\hline G17 & 154.3 & 153.3 & 148.3 & 149.3 & 152.7 & 151.3 & 154.0 & 152.7 & 152.3 & 153.7 & 154.0 & 153.0 & 152.4 & 1.9 & 0.520 & 2.86 \\
\hline Mean & 151.3 & 150.5 & 146.5 & 148.6 & 152.8 & 153.8 & 150.4 & 151.1 & 149.4 & 150.3 & 150.2 & 150.4 & 150.5 & & & \\
\hline $\operatorname{Ei}(\mathrm{Ij})$ & 0.8 & 0.0 & -4.0 & -1.9 & 2.3 & 3.3 & -0.1 & 0.6 & -1.1 & -0.2 & -0.3 & -0.1 & & & & \\
\hline $\begin{array}{l}\text { LSD } \\
(0.05)\end{array}$ & 2.84 & 2.64 & 2.55 & 2.66 & 2.73 & 2.63 & 1.17 & 1.03 & 0.95 & 1.00 & 1.47 & 1.53 & & & & \\
\hline
\end{tabular}

Genotype: G1= BRRI7A/BR1543-1-1-1-1, G2= BRRI11A/F2277R, G3= BRRI11A/BR1543-1-1-1-1, G4= BRRI13A/PR828R,G5= BRRI28A/BRRI26R, G6= BRRI48A/3028R, G7= BRRI48A/BRRI26R, G8= BRRI33A/BRRI31R, G9= Jin23A/PR344R, G10= BRRI11A/AGR, G11= IR79156A/BRRI20R, G12 $=$ BRRI53A/BRRI26R, G13 $=$ Jin23A/BR7881-25-2-3-12, G14= Jin23A/507R, G15= IR79156A/F2277R, G16= BRRI dhan28 and G17= BRRI dhan29

Environment: $A=$ Gazipur $1^{\text {st }}$ year, $B=$ Gazipur $2^{\text {nd }}$ year, $C=$ Gazipur $3^{\text {rd }}$ year, $D=R a n g p u r 1^{\text {st }}$ year, $\mathrm{E}=$ Rangpur $2^{\text {nd }}$ year, $\mathrm{F}=$ Rangpur $3^{\text {rd }}$ year, $\mathrm{G}=$ Comilla $1^{\text {st }}$ year, $\mathrm{H}=$ Comilla $2^{\text {nd }}$ year, $\mathrm{I}=$ Comilla $3^{\text {rd }}$ year, $\mathrm{J}=$ Satkhira $1^{\text {st }}$ year, $\mathrm{K}=$ Satkhira $=2^{\text {nd }}$ year and $\mathrm{L}=$ satkhira $3^{\text {rd }}$ year 
Table 5: Stability analysis for yield of 17 commercial rice hybrids over 12 environments.

\begin{tabular}{|c|c|c|c|c|c|c|c|c|c|c|c|c|c|c|c|c|}
\hline \multirow[t]{2}{*}{ Gn } & \multicolumn{12}{|c|}{ Environments } & \multirow{2}{*}{$\begin{array}{l}\text { Over } \\
\text { all } \\
\text { mean }\end{array}$} & \multirow[t]{2}{*}{$\mathrm{Pi}$} & \multirow[t]{2}{*}{ bi } & \multirow[t]{2}{*}{$\mathrm{S}^{2} \mathrm{di}$} \\
\hline & A & B & $\mathrm{C}$ & D & E & $\mathrm{F}$ & G & $\mathrm{H}$ & I & $\mathrm{J}$ & K & $\mathrm{L}$ & & & & \\
\hline G1 & 4.801 & 5.442 & 5.301 & 5.509 & 5.591 & 5.333 & 5.239 & 5.405 & 5.605 & 5.450 & 4.400 & 5.509 & 5.299 & -1.084 & $0.352^{*}$ & 0.10 \\
\hline G2 & 4.285 & 5.496 & 4.780 & 4.643 & 5.160 & 5.300 & 5.166 & 5.348 & 5.629 & 5.599 & 5.515 & 5.181 & 5.175 & -1.208 & $0.239^{*}$ & 0.17 \\
\hline G3 & 4.122 & 4.047 & 4.149 & 4.373 & 4.707 & 4.313 & 4.635 & 4.339 & 4.378 & 4.484 & 4.471 & 4.500 & 4.376 & -2.007 & $0.010^{*}$ & 0.04 \\
\hline G4 & 4.902 & 5.266 & 5.617 & 5.595 & 5.175 & 5.111 & 5.517 & 5.550 & 5.141 & 5.937 & 5.458 & 5.279 & 5.379 & -1.004 & $0.046^{*}$ & 0.09 \\
\hline G5 & 4.669 & 6.952 & 6.414 & 7.856 & 8.419 & 7.507 & 4.206 & 7.399 & 6.658 & 6.511 & 7.238 & 7.536 & 6.780 & 0.397 & 1.917 & 0.55 \\
\hline G6 & 6.766 & 6.366 & 6.926 & 6.279 & 6.832 & 6.730 & 7.053 & 6.526 & 6.519 & 5.756 & 5.784 & 6.123 & 6.472 & 0.089 & $-0.02 *$ & 0.20 \\
\hline G7 & 4.607 & 7.137 & 7.171 & 7.795 & 7.029 & 8.598 & 4.573 & 6.497 & 6.671 & 5.777 & 7.322 & 6.559 & 6.645 & 0.262 & $2.031^{*}$ & 0.27 \\
\hline G8 & 8.534 & 7.645 & 8.019 & 8.655 & 7.735 & 8.522 & 8.170 & 8.219 & 8.188 & 7.763 & 7.577 & 7.950 & 8.081 & 1.698 & $-0.034 *$ & 0.15 \\
\hline G9 & 6.410 & 7.162 & 7.115 & 7.292 & 7.578 & 7.767 & 6.569 & 7.649 & 7.677 & 7.432 & 6.717 & 7.444 & 7.234 & 0.851 & 0.683 & 0.08 \\
\hline G10 & 4.823 & 6.617 & 7.088 & 7.236 & 7.793 & 8.220 & 6.622 & 7.397 & 6.853 & 5.947 & 7.219 & 7.499 & 6.943 & 0.56 & 1.386 & 0.28 \\
\hline G11 & 5.214 & 8.036 & 7.803 & 7.706 & 7.194 & 9.062 & 6.376 & 7.561 & 6.509 & 6.735 & 7.273 & 5.668 & 7.095 & 0.712 & 1.596 & 0.45 \\
\hline G12 & 5.004 & 8.225 & 9.092 & 6.823 & 7.386 & 8.412 & 5.931 & 6.337 & 7.173 & 6.613 & 5.962 & 7.074 & 7.003 & 0.62 & 1.784 & 0.50 \\
\hline G13 & 4.656 & 7.951 & 7.756 & 7.750 & 8.618 & 8.698 & 4.628 & 6.828 & 7.556 & 7.098 & 6.720 & 6.201 & 7.038 & 0.655 & $2.368^{*}$ & 0.23 \\
\hline G14 & 5.771 & 7.954 & 7.778 & 8.176 & 8.627 & 8.460 & 6.210 & 5.768 & 7.410 & 6.485 & 5.331 & 7.203 & 7.098 & 0.715 & 1.712 & 0.54 \\
\hline G15 & 4.185 & 6.954 & 8.115 & 8.144 & 7.946 & 8.689 & 4.292 & 6.120 & 6.151 & 6.480 & 5.940 & 7.340 & 6.696 & 0.313 & $2.605^{*}$ & 0.24 \\
\hline G16 & 4.319 & 4.503 & 4.437 & 4.455 & 4.346 & 5.135 & 4.486 & 4.691 & 4.568 & 4.921 & 4.640 & 4.762 & 4.605 & -1.778 & $0.175^{*}$ & 0.05 \\
\hline G17 & 6.031 & 6.252 & 6.149 & 6.596 & 6.500 & 6.672 & 6.412 & 7.097 & 6.521 & 6.894 & 6.958 & 6.965 & 6.587 & 0.204 & $0.151^{*}$ & 0.12 \\
\hline Mean & 5.241 & 6.588 & 6.689 & 6.758 & 6.861 & 7.208 & 5.652 & 6.396 & 6.424 & 6.228 & 6.148 & 6.400 & 6.383 & & & \\
\hline $\mathrm{Ei}(\mathrm{Ij})$ & -1.142 & 0.205 & 0.306 & 0.375 & 0.478 & 0.825 & -0.731 & 0.013 & 0.041 & -0.155 & -0.235 & 0.017 & & & & \\
\hline LSD & 1.06 & 0.81 & 0.67 & 0.56 & 0.71 & 0.47 & 0.54 & 0.50 & 0.37 & 0.46 & 0.37 & 0.56 & & & & \\
\hline$(0.05)$ & & & & & & & & & & & & & & & & \\
\hline
\end{tabular}

Genotype: G1 = BRRI7A/BR1543-1-1-1-1, G2= BRRI11A/F2277R, G3= BRRI11A/BR1543-1-1-1-1, $\mathrm{G} 4=\mathrm{BRRI} 13 \mathrm{~A} / \mathrm{PR} 828 \mathrm{R}, \mathrm{G} 5=\mathrm{BRRI} 28 \mathrm{~A} / \mathrm{BRRI} 26 \mathrm{R}, \mathrm{G} 6=\mathrm{BRRI} 48 \mathrm{~A} / 3028 \mathrm{R}, \mathrm{G} 7=\mathrm{BRRI} 48 \mathrm{~A} / \mathrm{BRRI} 26 \mathrm{R}$, G8= BRRI33A/BRRI31R, G9 = Jin23A/PR344R, G10= BRRI11A/AGR, G11= IR79156A/BRRI20R, $\mathrm{G} 12=\mathrm{BRRI53A} / \mathrm{BRRI} 26 \mathrm{R}, \quad \mathrm{G} 13=\mathrm{Jin} 23 \mathrm{~A} / \mathrm{BR} 7881-25-2-3-12, \quad \mathrm{G} 14=\mathrm{Jin} 23 \mathrm{~A} / 507 \mathrm{R}, \quad \mathrm{G} 15=$ IR79156A/F2277R, G16= BRRI dhan28 and G17= BRRI dhan29

Environment: $\mathrm{A}=$ Gazipur $1^{\text {st }}$ year, $\mathrm{B}=$ Gazipur $2^{\text {nd }}$ year, $\mathrm{C}=$ Gazipur $3^{\text {rd }}$ year, $\mathrm{D}=$ Rangpur $1^{\text {st }}$ year, $\mathrm{E}=$ Rangpur $2^{\text {nd }}$ year, $\mathrm{F}=$ Rangpur $3^{\text {rd }}$ year, $\mathrm{G}=\mathrm{Comilla} 1^{\text {st }}$ year, $\mathrm{H}=$ Comilla $2^{\text {nd }}$ year, $\mathrm{I}=$ Comilla $3^{\text {rd }}$ year, $\mathrm{J}=$ Satkhira $1^{\text {st }}$ year, $\mathrm{K}=$ Satkhira $=2^{\text {nd }}$ year and $\mathrm{L}=$ satkhira $3^{\text {rd }}$ year 
Table 6: AMMI mean yield and IPCA1 scores for 17 rice hybrids grown in 12 environments.

\begin{tabular}{|c|c|c|c|}
\hline Genotypes & ID & AMMI mean yield $\left(\mathrm{tha}^{-1}\right)$ & IPCA1 scores \\
\hline BRRI7A/BR1543-1-1-1-1 & 1 & 5.299 & -0.462 \\
\hline BRRI11A/F2277R & 2 & 5.175 & -0.548 \\
\hline BRRI11A/BR1543-1-1-1-1 & 3 & 4.376 & -0.67 \\
\hline BRRI13A/PR828R & 4 & 5.379 & -0.638 \\
\hline BRRI28A/BRRI26R & 5 & 6.78 & 0.639 \\
\hline BRRI48A/3028R & 6 & 6.472 & -0.675 \\
\hline BRRI48A/BRRI26R & 7 & 6.645 & 0.748 \\
\hline BRRI33A/BRRI31R & 8 & 8.081 & -0.687 \\
\hline Jin23A/PR344R & 9 & 7.234 & -0.26 \\
\hline BRRI11A/AGR & 10 & 6.943 & 0.161 \\
\hline IR79156A/BRRI20R & 11 & 7.095 & 0.385 \\
\hline BRRI53A/BRRI26R & 12 & 7.003 & 0.57 \\
\hline Jin23A/BR7881-25-2-3-12 & 13 & 7.038 & 0.958 \\
\hline Jin23A/507R & 14 & 7.098 & 0.525 \\
\hline IR79156A/F2277R & 15 & 6.696 & 1.124 \\
\hline BRRI dhan28 & 16 & 4.605 & -0.565 \\
\hline BRRI dhan29 & 17 & 6.587 & -0.605 \\
\hline Environments & Year & & \\
\hline Gazipur & $1^{\mathrm{st}}$ & 5.241 & -1.359 \\
\hline Gazipur & $2^{\text {nd }}$ & 6.588 & 0.545 \\
\hline Gazipur & $3^{\text {rd }}$ & 6.689 & 0.664 \\
\hline Rangpur & $1^{\mathrm{st}}$ & 6.758 & 0.64 \\
\hline Rangpur & $2^{\text {nd }}$ & 6.861 & 0.765 \\
\hline Rangpur & $3^{\text {rd }}$ & 7.208 & 1.061 \\
\hline Comilla & $1^{\text {st }}$ & 5.652 & -1.426 \\
\hline Comilla & $2^{\text {nd }}$ & 6.396 & -0.317 \\
\hline Comilla & $3^{\text {rd }}$ & 6.424 & -0.079 \\
\hline Satkhira & $1^{\text {st }}$ & 6.228 & -0.329 \\
\hline Satkhira & $2^{\text {nd }}$ & 6.148 & -0.136 \\
\hline Satkhira & $3^{\text {rd }}$ & 6.400 & -0.027 \\
\hline
\end{tabular}




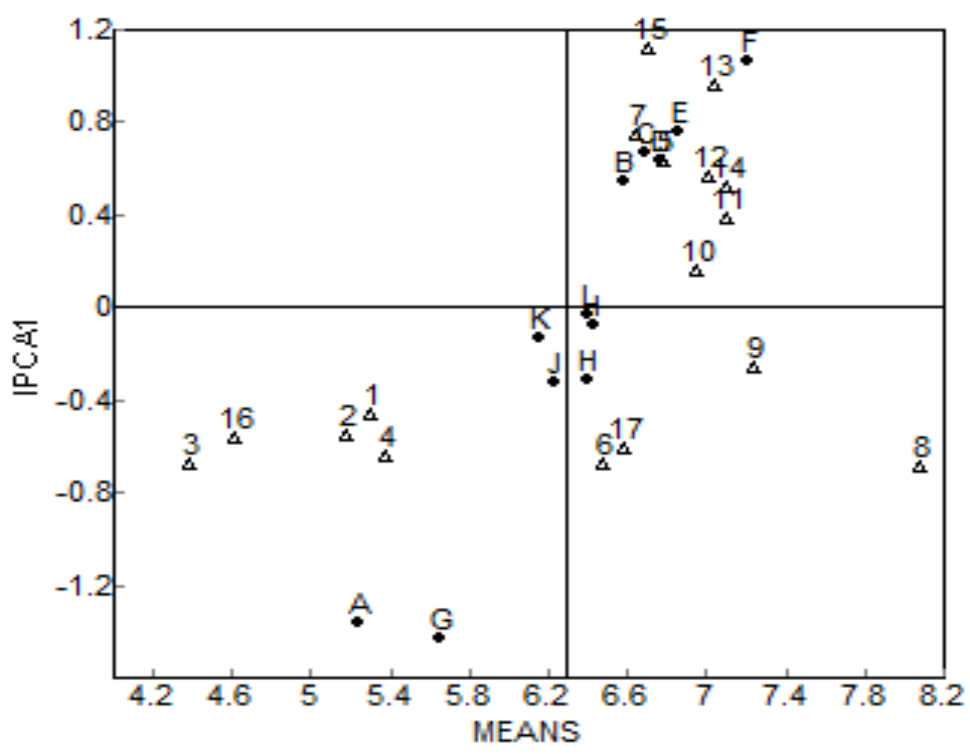

Figure 1: Biplot of the first AMMI interaction (IPCA 1) score (Y-axis) plotted against mean yield $\left(\mathrm{t} \mathrm{ha}^{-1}\right)$ (X-axis) for seventeen hybrid rice genotypes over 12 environments.

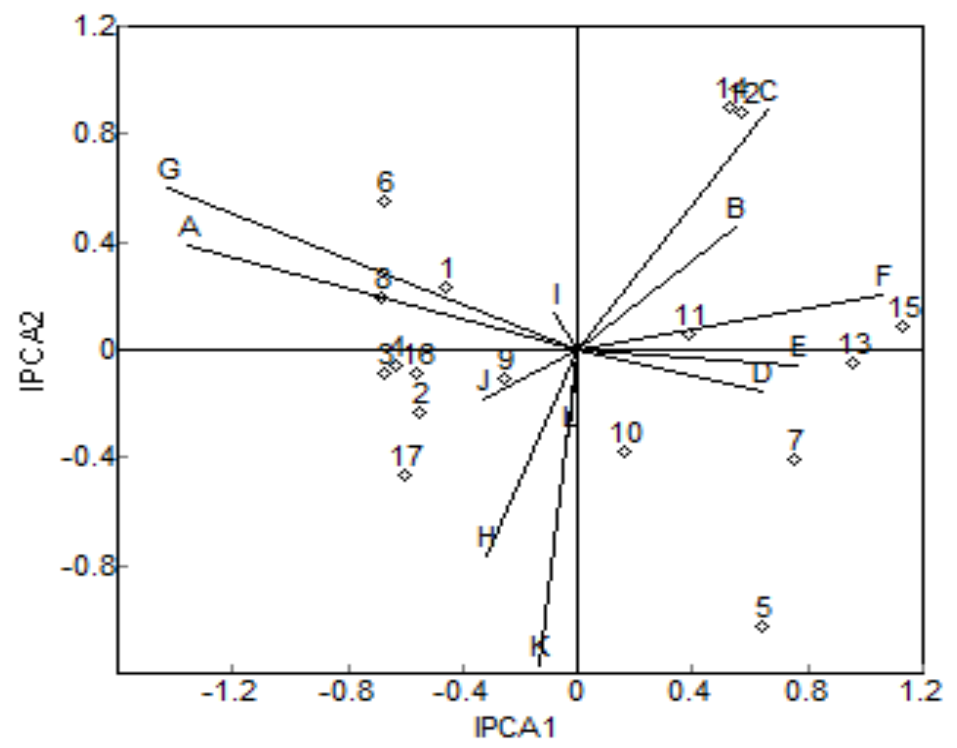

Figure 2: Graphic of AMMI biplot interaction of seventeen genotypes over 12 environments.

In graph, it is better to write the genotype name instead of just number 